\title{
Pathogenic characteristics of persistent feline enteric coronavirus infection in cats
}

\author{
Liesbeth Vogel ${ }^{1}$, Mariken VAn der LubBen ${ }^{1}$, Eddie G. Te Lintelo ${ }^{1}$, \\ Cornelis P.J. BeKkeR ${ }^{1}$, Tamara Geerts ${ }^{1}$, Leontine S. SchuijfF ${ }^{1}$, \\ Guy C.M. Grinwis ${ }^{2}$, Herman F. EgBerink ${ }^{1}$, Peter J.M. RotTier ${ }^{1 *}$ \\ ${ }^{1}$ Virology Division, Department of Infectious Diseases and Immunology, Faculty of Veterinary Medicine, \\ Utrecht University, Yalelaan 1, 3584 CL Utrecht, The Netherlands \\ ${ }^{2}$ Pathology Division, Department of Pathobiology, Faculty of Veterinary Medicine, Utrecht University, \\ Yalelaan 1, 3584 CL Utrecht, The Netherlands
}

(Received 22 March 2010; accepted 20 July 2010)

\begin{abstract}
Feline coronaviruses (FCoV) comprise two biotypes: feline enteric coronaviruses (FECV) and feline infectious peritonitis viruses (FIPV). FECV is associated with asymptomatic persistent enteric infections, while FIPV causes feline infectious peritonitis (FIP), a usually fatal systemic disease in domestic cats and some wild Felidae. FIPV arises from FECV by mutation. FCoV also occur in two serotypes, I and II, of which the serotype I viruses are by far the most prevalent in the field. Yet, most of our knowledge about FCoV infections relates to serotype II viruses, particularly about the FIPV, mainly because type I viruses grow poorly in cell culture. Hence, the aim of the present work was the detailed study of the epidemiologically most relevant viruses, the avirulent serotype I viruses. Kittens were inoculated oronasally with different doses of two independent FECV field strains, UCD and RM. Persistent infection could be reproducibly established. The patterns of clinical symptoms, faecal virus shedding and seroconversion were monitored for up to 10 weeks revealing subtle but reproducible differences between the two viruses. Faecal virus, i.e. genomic RNA, was detected during persistent FECV infection only in the large intestine, downstream of the appendix, and could occasionally be observed also in the blood. The implications of our results, particularly our insights into the persistently infected state, are discussed.
\end{abstract}

coronavirus / experimental infection / FECV / persistence / cat

\section{INTRODUCTION}

Feline coronaviruses (FCoV) present themselves in different forms. First of all there are two biotypes, the low- or avirulent viruses and the highly virulent ones. The former viruses cause intestinal infection with no or only mild clinical manifestations, i.e. diarrhoea in young kittens. These so-called feline enteric coronaviruses $(\mathrm{FECV})$ are the predominant pathotype

\footnotetext{
*Corresponding author: p.rottier@uu.nl
}

in the field. FECV infection often persists in apparently healthy animals, which shed the virus in their faeces. Natural infection occurs via the faecal-oral route. FECV infection appears to be mainly restricted to the intestinal tract where the virus replicates in villous epithelial cells. The virulent pathotype, feline infectious peritonitis virus (FIPV), causes severe systemic infection with lesions in many organs and tissues, most typically in the peritoneum, hence the disease's name feline infectious peritonitis (FIP). Unlike FECV, FIPV does not spread readily 
among cats. Instead, it originates de novo by spontaneous mutation from FECV in individual animals $[4,24,26,30]$ often under conditions of immune suppression due to medication or coinfection [26]. FIP is a highly fatal disease that occurs in domestic cats and some wild felidae usually between 3 and 16 months of age. The disease is currently the leading infectious cause of death in domestic cats. In catteries 80 to $90 \%$ of the animals are usually feline coronavirus seropositive, in single cat households seropositivity often varies between 10 and 50\% [20]. From the seropositive cats, 5 to $12 \%$ eventually develop FIP [1]. There is at present no effective way to prevent the infection or treat the disease. For recent reviews on $\mathrm{FCoV}$, see Haijema et al. [11] and Pedersen [25].

FCoV also occur as two serotypes. Based on in vitro neutralization tests, serotypes I and II have been distinguished $[15,25]$, which can in turn be of either pathotype. In the field the serotype I viruses are largely predominant; they are responsible for 70 to $95 \%$ of $\mathrm{FCoV}$ morbidity and mortality. In Europe and in the USA type II viruses are quite rarely observed, in contrast to Japan where they were reported to constitute some 20 to $30 \%$ of all viruses [16].

Research on FCoV infection has understandably focused mainly on FIPV, its origin, its particular pathogenesis and disease. Moreover, most of what we know about these viruses comes from work with serotype II viruses, simply because efficient in vitro propagation of serotype I viruses has not yet been achieved. Hence, in order to learn more about the characteristics of the most prevalent FCoV infection in the field, we have in this study set up animal infection systems for serotype I FECV. Using two independent field isolates we reproducibly observed persistent infection of which we evaluated the clinical, virological and serological features.

\section{MATERIALS AND METHODS}

\subsection{Viruses}

Faecal extracts containing an unknown titre of FECV strain UCD [23] and FECV strain RM [26] were kindly provided by N.C. Pedersen and A. Poland (both Davis, CA, USA), respectively. They were used to prepare stocks of these viruses for our infection experiments as follows. Specific pathogen-free (SPF) kittens were inoculated oronasally with an aliquot of the faecal sample. Faeces were collected daily and suspended in an equal volume of phosphate buffered saline (PBS). The suspensions were centrifuged at $3000 \times g$ for $10 \mathrm{~min}$ and the viral genome contents in the supernatants determined by quantitative RTPCR (see below). Extracts with the highest concentrations of viral RNA were combined, aliquoted and stored frozen at $-80{ }^{\circ} \mathrm{C}$. The RNA content of the FECV UCD and FECV RM stocks were $1 \times 10^{6}$ and $4 \times 10^{7}$ genome equivalents per $\mu \mathrm{L}$, respectively.

\subsection{Cats}

SPF cats (Harlan Sprague Dawley, Inc., Madison, USA), seronegative for FCoV as checked by standard immunofluorescence assay, were used in all infection experiments. The animals were housed in groups in a closed animal facility. They were euthanized at the indicated end of each experiment by intravenous injection with an overdose of phenobarbital. For all experiments, approval of the university's Ethical Committee was obtained.

\subsection{Design of animal infection experiments}

With the aim to reproducibly establish persistence by experimental FECV infection, to elucidate possible differences in pathogenic characteristics among different strains, and to investigate possible dose-dependent differences in these characteristics, four experimental infections were performed, two with each of the FECV strains. In the first experiment with FECV UCD (experiment A1, Tab. I) two male SPF cats of 11 weeks old were inoculated oronasally each with $0.5 \mathrm{~mL}$ (i.e. $5 \times 10^{8}$ genome equivalents) of the FECV UCD faecal extract. The animals were monitored during 35 days post inoculation for clinical signs, faecal virus shedding and serum antibody titres. In the second infection experiment with FECV UCD (experiment A2, Tab. I) eight female SPF cats, 11 weeks old and housed in four groups of two animals, were inoculated oronasally with $0.5 \mathrm{~mL}$ per cat of a series of 10-fold dilutions of the FECV UCD stock: undiluted and diluted $10^{-1}, 10^{-2}$ and $10^{-3}$ in PBS (two cats per dose). The cats were monitored for clinical signs, body weight, faecal virus shedding and serum antibody titres for 70 days post inoculation.

In the first infection experiment with FECV RM (experiment B1, Tab. I) four female SPF cats of 18 weeks old were inoculated oronasally with $0.5 \mathrm{~mL}$ 
Table I. Overview of the experimental set-up.

\begin{tabular}{lccccccc}
\hline Exp. no. & $\begin{array}{c}\text { FECV } \\
\text { strain }\end{array}$ & $\begin{array}{c}\text { Virus doses } \\
\text { (genome equivalents/ } \mu \mathrm{L})\end{array}$ & Dilutions & No. of cats & $\begin{array}{c}\text { Age } \\
\text { (weeks) }\end{array}$ & Sex & $\begin{array}{c}\text { Observ. period } \\
\text { (days) }\end{array}$ \\
\hline A1 & UCD & $5 \times 10^{8}$ & Undiluted & 2 & 11 & $\mathrm{M}$ & 35 \\
\hline A2 & UCD & $5 \times 10^{8}$ & Undiluted & 2 & & & \\
& & $5 \times 10^{7}$ & $10^{-1}$ & 2 & 11 & $\mathrm{~F}$ & 70 \\
& & $5 \times 10^{6}$ & $10^{-2}$ & 2 & & & \\
\hline B1 & RM & $2 \times 10^{5}$ & $10^{-3}$ & 2 & & & 71 \\
\hline B2 & RM & $2 \times 10^{10}$ & Undiluted & 4 & 18 & $\mathrm{~F}$ & 70 \\
& & $2 \times 10^{8}$ & Undiluted & 2 & & & \\
& & $2 \times 10^{7}$ & $10^{-2}$ & 2 & 18 & $\mathrm{~F}$ & 70 \\
& & $2 \times 10^{6}$ & $10^{-4}$ & 2 & & & \\
\hline
\end{tabular}

(i.e. $2 \times 10^{10}$ genome equivalents) of the FECV RM faecal extract and monitored similarly for 71 days post inoculation. In the second experiment with this virus (experiment B2, Tab. I) eight female SPF cats, 18 weeks old and housed in pairs, were inoculated oronasally with $0.5 \mathrm{~mL}$ per cat of several dilutions of the FECV RM stock: undiluted and diluted $10^{-2}, 10^{-3}$ and $10^{-4}$ in PBS (two cats per dose). They were again monitored for the standard parameters for 70 days post inoculation.

Monitoring of clinical signs was done on a daily basis by scoring for such signs as depression, general activity, anorexia and faeces consistency. The body temperature and body weight were determined once or twice a week. Body weight was expressed as the percentage of the body weight measured at the day of inoculation.

\subsection{Quantitative RT-PCR}

To monitor faecal virus shedding, quantitative RTPCR was performed using the TaqMan ${ }^{\circledR}$ procedure described by Gut et al. [9], which targets the conserved $7 \mathrm{~b}$ gene in the $3^{\prime}$ domain of the FCoV genome. To extract template RNA from faecal samples, faeces were weighed, suspended and diluted 1:1 (w/v) with PBS and centrifuged at $3000 \times g$ for $10 \mathrm{~min}$ to remove large particles. RNA was extracted from the suspension using guanidinium thiocyanate with adsorption of viral RNA onto silica as described by Boom et al. [3]. The eluted RNA was diluted 1:10 in TE buffer $(10 \mathrm{mM}$ Tris-HCl, $1 \mathrm{mM}$ EDTA, $\mathrm{pH}$ $8.0)$ before addition to the PCR mixture.

The $25 \mu \mathrm{L}$ PCR mixture contained $12.5 \mu \mathrm{L}$ Master Mix and $0.63 \mu \mathrm{L}$ Multiscribe and RNase Inhibitor Mix (Applied Biosystems, Nieuwerkerk $\mathrm{a} / \mathrm{d}$ IJssel, The Netherlands), $0.2 \mu \mathrm{M}$ forward primer
FCoV1128f, $2 \mu \mathrm{M}$ reverse primer FCoV1229r, $0.3 \mu \mathrm{M}$ probe $\mathrm{FCoV} 1200 \mathrm{p}$ and $2 \mu \mathrm{L}$ template RNA or diluted standard (described in next paragraph). After a reverse transcription step of $30 \mathrm{~min}$ at $48^{\circ} \mathrm{C}$ and a denaturation step of $10 \mathrm{~min}$ at $95{ }^{\circ} \mathrm{C}, 40$ cycles, each $15 \mathrm{~s}$ at $95{ }^{\circ} \mathrm{C}$ and $1 \mathrm{~min}$ at $60^{\circ} \mathrm{C}$, were performed. Reverse transcription, amplification and real time monitoring of fluorescence were carried out in an ABI Prism ${ }^{\circledR} 7000$ Sequence Detector.

A synthetic RNA standard for absolute quantification was produced using as a template the pST-blue102 plasmid (kindly provided by Virbac Laboratories Inc., Carros, France) containing a cDNA copy of the RNA fragment to be amplified in our assay behind the T7 RNA promoter. The transcription reaction sample was DNAse-treated, the RNA purified by phenol/chloroform extraction and isopropanol precipitation, and the amount of RNA determined by UV spectrophotometry. The RNA stock was aliquoted and frozen at $-80{ }^{\circ} \mathrm{C}$. RNA dilutions were tested by TaqMan ${ }^{\circledR}$ analysis, showing a linear relationship between the amount of input RNA and the $\mathrm{Ct}$ value over a range of at least $5 \log$ units, corresponding to $3 \times 10^{3}$ through $3 \times 10^{8}$ molecules (data not shown).

\subsection{Radioimmunoprecipitation assay (RIPA)}

Twenty-five $\mu \mathrm{L}$ of ${ }^{35} \mathrm{~S}$-methionine labelled FCoV (strain 79-1146) infected cell lysate was mixed with $1 \mathrm{~mL}$ TESV buffer (20 mM Tris-HCl pH 7.3, $1 \mathrm{mM}$ EDTA, $100 \mathrm{mM} \mathrm{NaCl}$ ) containing 1\% Triton X100, $0.1 \mathrm{mg} / \mathrm{mL}$ BSA (Sigma A-7888, Sigma Aldrich, Zwijndrecht, The Netherlands) and $0.25 \%$ SDS, to which $15 \mu \mathrm{L}$ cat serum was added. Ascitis (\#9912; $3 \mu \mathrm{L}$ ), obtained from an experimentally FIPV 79-1146 (serotype II) infected cat [10], and anti-RM 
plasma $(15 \mu \mathrm{L})$, obtained from a FECV RM (serotype I) infected cat, were used as positive controls. The mixtures were incubated overnight at $4{ }^{\circ} \mathrm{C}$. The immune complexes were adsorbed to $50 \mu \mathrm{L}$ Pansorbin cells (Calbiochem; Merck KGaA, Darmstadt, Germany) for $30 \mathrm{~min}$ at $4{ }^{\circ} \mathrm{C}$. After centrifugation the pellets were washed three times with RIPA-buffer $(10 \mathrm{mM}$ Tris- $\mathrm{HCl} \mathrm{pH} 7.4,0.1 \%$ SDS, $1 \%$ DOC (w/v), 1\% NP40 and $150 \mathrm{mM} \mathrm{NaCl})$. The final pellets were resuspended in Laemmli sample buffer and heated at $95{ }^{\circ} \mathrm{C}$ for $1 \mathrm{~min}$. The precipitates were analysed by SDS-PAGE using a $10 \%$ polyacrylamide gel. After electrophoresis the gel was fixed in $50 \%$ methanol containing $10 \%$ acetic acid, dried and the radioactivity visualized by autoradiography.

\subsection{ELISA}

Serum antibody titres were determined by a typespecific ELISA. Microtiter plates (96 wells; Microlon, Greiner Bio-one International B.V., Alphen a/d Rijn, The Netherlands) were coated with $200 \mathrm{ng}$ whole virus particles of a cell culture adapted derivative of the serotype I FCoV strain UCD-1 [22]. The virus was grown on felis catus whole fetus (fcwf-4) cells [22], which were maintained as monolayer cultures in Dulbecco's modified Eagle's medium containing $10 \%$ foetal calf serum, $100 \mathrm{IU}$ of penicillin $/ \mathrm{mL}$, and $100 \mu \mathrm{g}$ of streptomycin $/ \mathrm{mL}$ (all from Life Technologies Ltd., Paisley, UK). The virus was purified from the clarified cell culture supernatant by ultracentrifugation through a $20 \%(\mathrm{w} / \mathrm{w})$ sucrose cushion. Pellets were resuspended in TM buffer $\left(20 \mathrm{mM}\right.$ Tris- $\mathrm{HCl}$ and $20 \mathrm{mM} \mathrm{MgCl}{ }_{2}$ adjusted to $\mathrm{pH}$ 7.0) and protein content determined with the Bio-Rad DC Protein Assay (Bio-Rad Laboratories B.V., Veenendaal, The Netherlands). The plates were incubated with the virus, dissolved in $0.1 \mathrm{M}$ carbonate buffer $\mathrm{pH} 9.6$, for $1.5 \mathrm{~h}$ at $37^{\circ} \mathrm{C}$ and overnight at $4{ }^{\circ} \mathrm{C}$. Plates were blocked with $1 \%$ BSA in PBSTween $20(0.05 \%)$ for $1 \mathrm{~h}$ at $37^{\circ} \mathrm{C}$. The plates were washed three times with PBS-Tween20 $(0.05 \%)$, 2 -fold serial dilutions of cat serum in PBS-Tween20 were added to the wells and the plates were incubated at room temperature for $1 \mathrm{~h}$. After washing the plates again with PBS-Tween20, peroxidase-conjugated goat anti-cat IgG (Cappel Laboratories Inc., Downingtown, USA) was added to the wells and the plates were again incubated at room temperature for $1 \mathrm{~h}$. Subsequently, the plates were rinsed and $100 \mu \mathrm{L}$ substrate solution containing $0.1 \mathrm{mg} / \mathrm{mL}$ tetramethylbenzidine- $\mathrm{H}_{2} \mathrm{O}_{2}$ in $0.1 \mathrm{M}$ sodium acetate was added to the wells. The substrate reaction was stopped by the addition of $50 \mu \mathrm{L} 2 \mathrm{M} \mathrm{H}_{2} \mathrm{SO}_{4}$. The absorbance at $450 \mathrm{~nm}$ was determined on a EL808 Ultra Microplate Reader (BioTek Instruments, Inc., Winooski, USA). A titration curve was obtained by plotting the optical density as a function of the reciprocal serum dilution. The titre was defined as the highest dilution of serum corresponding to an optical density of 0.2 above the background, as extrapolated from the slope of the curve (background values were determined using a FCoV negative serum). The significance of the differences in the serum antibody titres was analyzed using Student's $t$-test.

\subsection{Detection of viraemia}

In order to detect the presence of viral RNA in blood, EDTA blood was centrifuged for $10 \mathrm{~min}$ at $2500 \mathrm{rpm}$. After separation of the plasma one volume of PBS was added to the blood cells and total RNA was isolated using the Total Quick RNA Blood Kit Protocol (Talent, Trieste, Italy). Quantitative RTPCR to detect viral genomic RNA was performed as described above. For the detection of subgenomic mRNA we used a RT-PCR protocol targeting the mRNA specifying the viral membrane (M) protein as described earlier [28].

\subsection{Localization of virus in the gut}

To longitudinally screen the intestinal tract of persistently FECV infected cats for virus, the intestines of freshly euthanized animals were sectioned over their entire length into segments of $5 \mathrm{~cm}$ (first part until appendix) or $1 \mathrm{~cm}$ (remainder). The faecal content of each segment was collected in an eppendorf tube and subsequently the tissue segment was washed out thoroughly with cold PBS. The faecal material was suspended in an equal volume of PBS and centrifuged for $20 \mathrm{~min}$ at $3000 \mathrm{rpm}$. The supernatant was collected, RNA was extracted and the viral genome content was quantitated by real-time RT-PCR as described above. For RNA isolation from the intestinal tissue, the washed segments were lysed overnight in lysis buffer L6 and subsequently the RNA was purified and concentrated by the guanidinium thiocyanate-silica ( $\mathrm{SiO} 2)$ protocol of Boom et al. [3].

\subsection{Immunohistochemistry of gut tissue sections}

Segments of the gut found FCoV positive by RTPCR were stained for the presence of antigen within cells. Sections of the gut were deparaffinized in xylene and rehydrated through graded alcohols. After 
pretreatment of the slides with citrate buffer $\mathrm{pH} 6.0$ and heating using a microwave oven, endogenous peroxidase activity was blocked using hydrogen peroxide $(1 \%)$ in methanol and subsequently sections were blocked with normal goat serum. After incubation with a primary antiserum (mouse anti-feline coronavirus MCA2194, AbD Serotec, Düsseldorf, Germany) a goat anti mouse Envision complex was added (Dako, Heverlee, Belgium). Subsequently sections were incubated with 3,3'-diaminobenzidine tetrahydrochloride and counterstained with Papanicolaou's hematoxylin.

\section{RESULTS}

\subsection{Infection of cats with FECV UCD and FECV RM}

Experiments A1 and B1 (Tab. I) were performed to comparatively analyse the clinical, virological and serological course of an infection with two different avirulent serotype I FECV strains and to investigate whether persistent infection could be established. FECV UCD and FECV RM are independent virus isolates, maintained in cats only, and first described by Pedersen et al. [23] and Hickman et al. [14], respectively. The viruses were applied by the natural route, i.e. by oronasal inoculation. Two cats were inoculated with FECV UCD and four cats with FECV RM.

All six cats were successfully infected and both infections persisted as indicated by faecal virus shedding which lasted for at least 35 days (strain UCD) and 71 days (strain RM), i.e. until the time the experiment was terminated and the animals euthanized. Faecal virus shedding, as monitored by TaqMan ${ }^{\circledR}$ RT-PCR, became readily detectable from day 1 to 3 post inoculation and increased rapidly up to $10^{7}$ genomes $/ \mu \mathrm{L}$ faeces in all animals. All cats seroconverted as determined both by RIPA and by ELISA (data not shown; detailed data are provided below for the dose-titration experiments).

The two cats inoculated with FECV UCD had diminished appetite at several days in the period between day 5 and day 16 after inoculation and experienced weight loss during the first eight days after inoculation. The cats inoculated with FECV RM did not show any clinical signs of disease during the entire experimental period.
They exhibited normal behaviour and the consistency of their faeces was also normal.

\subsection{Effect of inoculation dose on infection outcome}

To obtain a more detailed and comparative insight into FECV UCD and FECV RM infection and into the effect of virus dose on the outcome and persistence of infection, experiments A2 and B2 were performed. In both these experiments eight cats placed in groups of two were inoculated with different doses of the two viruses, ranging from $5 \times 10^{5}$ to $2 \times 10^{10}$ genome equivalents. All cats, even those inoculated with the lowest viral dose, became infected, as indicated by their faecal virus shedding and seroconversion. Virus shedding became detectable already one day after inoculation with the two highest doses of FECV UCD and two days after inoculation of the cats with the two lowest doses of this virus. Shedding of FECV RM was first detected at day 2 in the animals that received the two highest doses and on day 3 in the cats inoculated with the two lowest doses (Fig. 1). In all animals, the amount of virus in the faeces subsequently increased within two days to peak levels of $10^{6}-10^{8}$ genomes $/ \mu \mathrm{L}$ faeces, after which shedding remained high for an extended period until day 16 and day 23 post inoculation in FECV UCD and FECV RM infected cats, respectively. Thereafter the virus titres in the faeces declined. Shedding seemed to decline more steeply in cats that had received the lowest viral doses. This was particularly the case for the FECV RM infected animals where virus was no longer detected from day 42 after inoculation with the $10^{-3}$ or $10^{-4}$ diluted doses.

\subsection{Serological responses to infection}

All cats developed FCoV-specific serum antibodies as determined by ELISA and RIPA (Figs. 2 and 3). The kinetics of appearance of the antibodies was comparable for both viruses. As illustrated for the FECV UCD infections in Figure 2, the antibodies started to become detectable at 10 days post inoculation. There was a clear tendency for the animals infected with the higher doses to develop somewhat higher, 

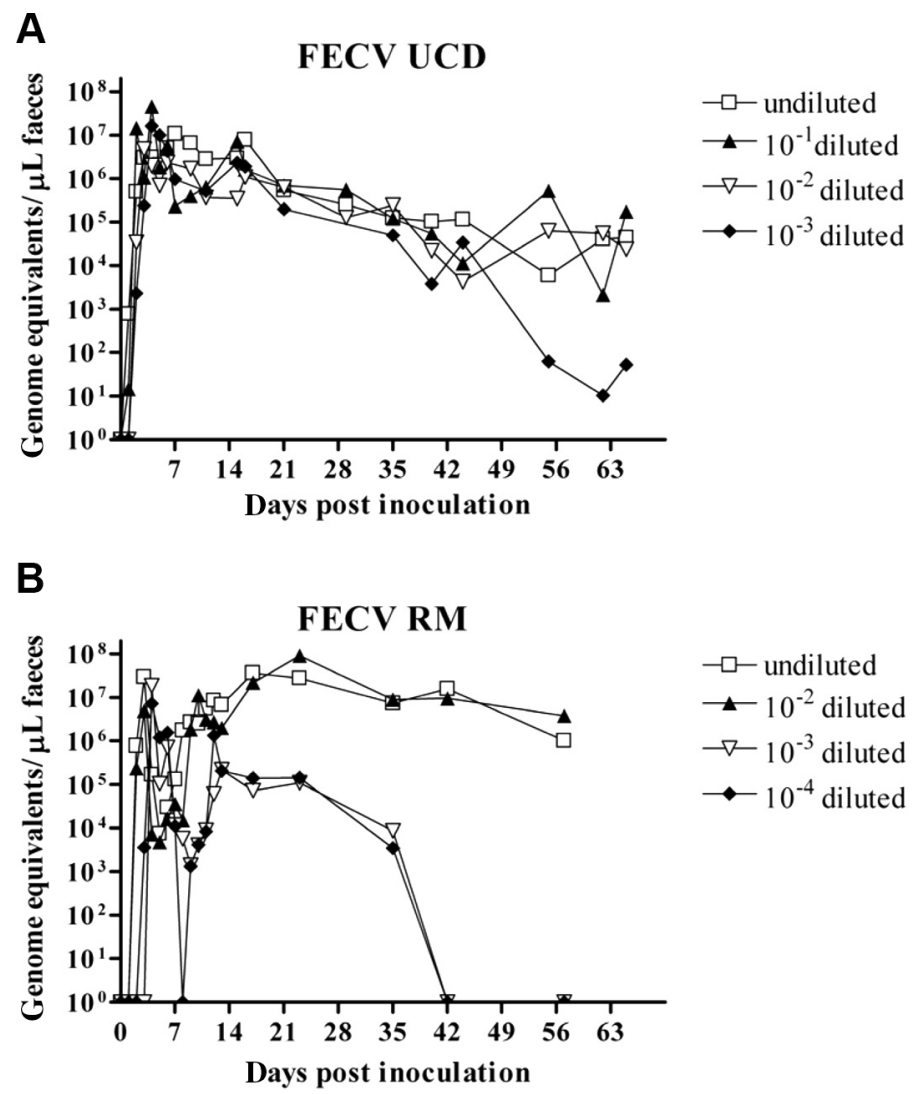

Figure 1. Faecal shedding of virus by cats included in infection experiments $\mathrm{A} 2$ and $\mathrm{B} 2$ after inoculation with FECV UCD (A) or FECV RM (B), as monitored by TaqMan ${ }^{\circledR}$ RT-PCR. Means per group $(n=2)$. Note that RNA quantities below $3 \times 10^{3}$ cannot be considered accurate (real quantities are probably lower) due to the non-linear relationship between input RNA and $\mathrm{Ct}$ value in the assay in the lower concentration range.

longer-lasting ELISA titres. The elicited antibodies recognized the FCoV structural proteins $\mathrm{M}, \mathrm{N}$ and $\mathrm{S}$ as determined by RIPA (Fig. 3). Antibodies to the $\mathrm{N}$ protein were predominant and the first to become detectable by this assay.

\subsection{Clinical observations}

All FECV UCD infected cats showed diminished appetite between days 3 through 15 post inoculation, resulting in loss of body weight gain (Fig. 4). However, the animals produced normal stools and did not show any other signs of disease, with the exception of two cats. One cat, inoculated with undiluted faecal extract, developed a chronic fever at day 5, which subsided after day 40. The other cat, inoculated with $10^{-3}$ diluted faecal extract, developed a recurring fever, with temperatures $\geq 40{ }^{\circ} \mathrm{C}$ on days $2,26,35,40$ and 62 post inoculation. The body temperature of the remaining cats stayed between 37.6 and $40.0{ }^{\circ} \mathrm{C}$ throughout the experiment. Interestingly, two cats, inoculated with a $10^{-3}$ and a $10^{-2}$ dilution, respectively, which were apparently able to contain the persistent infection and to reduce viral titres in the faeces, showed a stronger increase in body weight than the other animals (Fig. 4). 


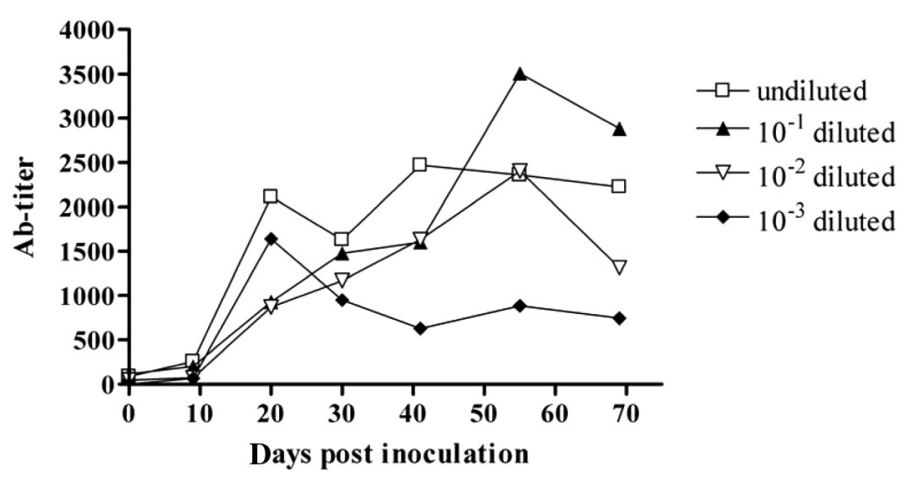

Figure 2. Serum antibody titres, detected with ELISA, in cats included in infection experiment A2 after inoculation with FECV UCD. Means per group $(n=2)$.

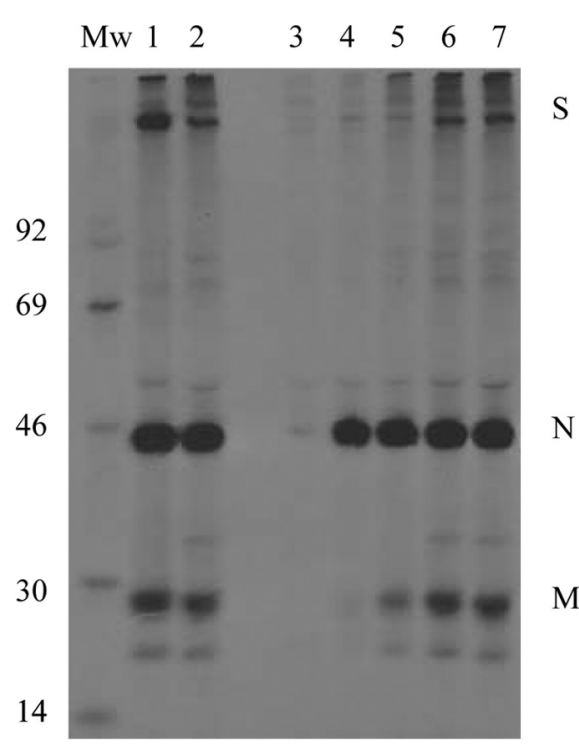

Figure 3. RIPA with serum from one representative cat inoculated with a $10^{-2}$ diluted dose of FECV RM (experiment B2). A lysate of ${ }^{35}$ S-methionine labelled FCWF cells infected with FIPV strain 79-1146 was used for the immunoprecipitations. MW: molecular weight markers, of which the molecular sizes $(\mathrm{kDa})$ are indicated at the left; lane 1; ascitis 9912; lane 2: anti-RM plasma; lane 3-7: serum collected from the cat one day before inoculation and at days 13,23, 43 and 50 after inoculation, respectively. Note the relatively poor recognition of the serotype II viral spike (S) protein by the serotype I sera.
The FECV RM infected cats grew normally, without weight loss or growth retardation, and showed no clinical signs of disease during the entire experimental period. The disease signs observed with the UCD strain are thus unlikely to be caused by experimental conditions such as manipulation-induced stress.

The FECV infections had no effects on the number of peripheral blood lymphocytes. Their numbers remained stable irrespective of the viral strain or dose when counted at various times post inoculation (data not shown).

\subsection{Viral RNA in blood}

The presence of virus in blood was tested by performing a real-time RT-PCR on whole EDTA blood of FECV UCD infected cats. The results of these assays were variable. Often no viral RNA was detected and, if positive, no clear pattern was observed, as illustrated by Figure 5. No sign of viral replication in the blood of these two animals could be detected as judged by an RT-PCR assay targeting subgenomic mRNA for the viral M protein.

\subsection{Post mortem localization of virus in the digestive tract during viral persistence}

In order to determine in which part(s) of the gut virus was present during viral persistence, 


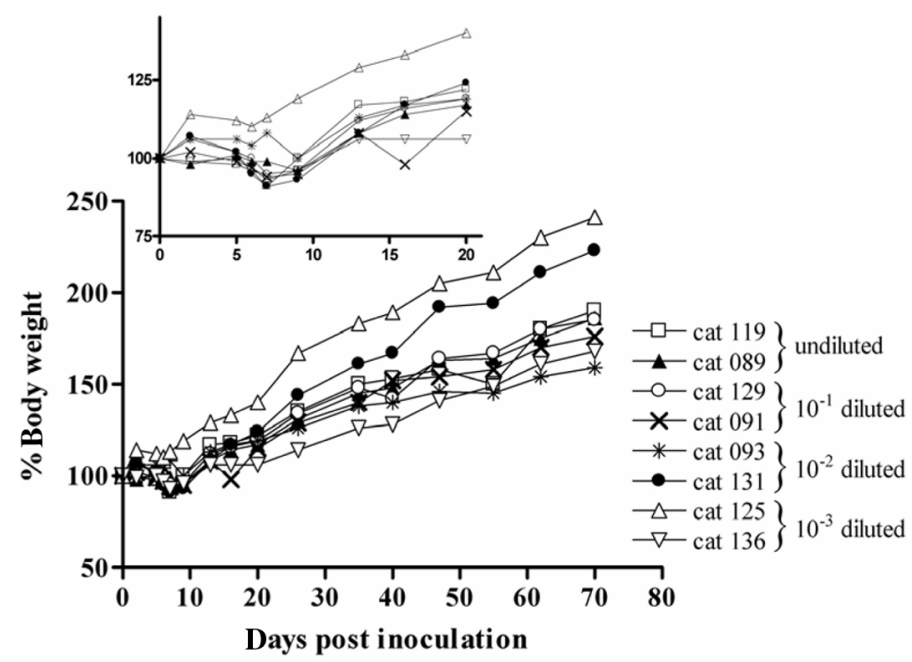

Figure 4. Body weight of FECV UCD-inoculated cats included in infection experiment A2. Cats 119 and 089 were inoculated with undiluted faecal extract, cats 129 and 091 with a $10^{-1}$ dilution, cats 093 and 131 with a $10^{-2}$ dilution, and cats 125 and 136 with a $10^{-3}$ dilution of the faecal extract. The upper figure shows an expanded view of the initial phase of the infection.
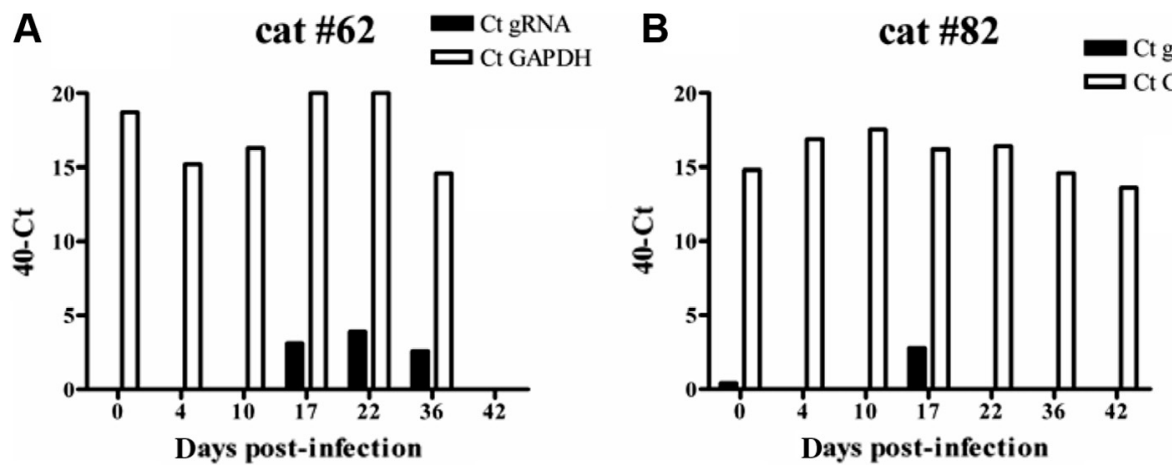

Figure 5. Viral genomic RNA in blood. Two 17 -weeks-old cats were inoculated with a $10^{-2}$ dilution of FECV UCD stock. Genomic RNA was determined in blood cells by real-time RT-PCR.

we screened the contents of the entire intestines of two FECV UCD infected cats. These animals, from a similar infection experiment not described here, were still shedding virus at days 64 and 68 days post inoculation, the time they were euthanized. Their intestines were sectioned over their entire length in 5-cm (from stomach up to the appendix) and $1-\mathrm{cm}$ segments (remainder). Viral RNA in each segment was determined by real-time RT-PCR. As shown in Figure 6, no virus was detectable in the first approximately $150 \mathrm{~cm}$ long part comprising duodenum, jejunum and ileum. In both animals virus was found only in the approximately $15-20 \mathrm{~cm}$ final part of the gut, downstream of the appendix, i.e. in colon and rectum. While viral RNA was found in the faeces part of essentially all segments of these 

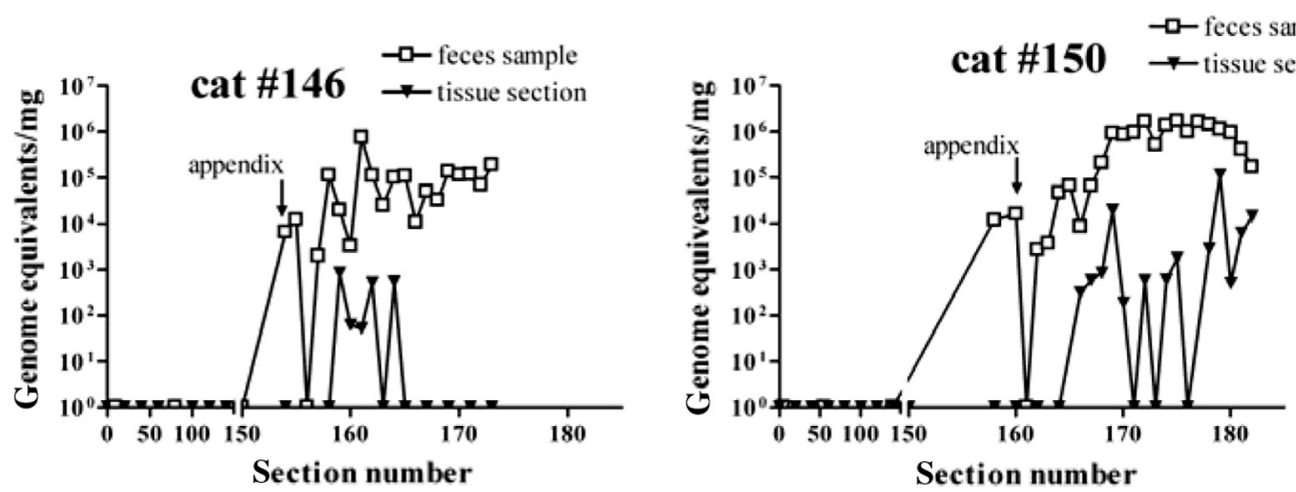

Figure 6. Virus in the intestinal tract during persistent FECV infection. Two cats inoculated with a $10^{-1}$ dilution of FECV UCD stock were euthanized 64 and 68 days later while still shedding virus. Intestines were sectioned into $5-\mathrm{cm}$ (from stomach to appendix) and 1-cm segments (downstream of appendix) and the viral RNA in faecal content and intestinal tissue was determined for each segment by real-time RT-PCR. Section numbers refer to the following parts of the gut. For cat 146: 1-10, duodenum; 10-156, jejunum and ileum; 157-166, colon; 167-177, rectum. For cat 150: 1-10, duodenum; 10-160, jejunum and ileum; 160 177, colon; 178-184, rectum.

compartments, no viral RNA could be detected in several of the corresponding tissue specimens, suggesting that at this late stage of persistence the number or areas of virus-producing cells have become scarce. Consistent with this interpretation, attempts to visualize infected cells in fixed sections of the epithelial lining of the intestines by immunoperoxidase staining were unsuccessful.

\section{DISCUSSION}

While there is quite a number of reports describing natural infections caused by the prevalent serotype I FCoV [1, 2, 6-8, 13, 17, 21], studies investigating the course of FECV infection after controlled experimental infection are remarkably few $[6,21,23,24]$. Yet, such studies are important as detailed knowledge about the biology of this infection should eventually allow us to better understand the conditions and requirements that give rise to the fatal pathotypic shift to FIP. These insights in turn might provide leads to prevent this transition or treat the disease. Here we describe the results of four infection experiments in which persistent infection was reproducibly established and in which we analysed a number of clinical, virological and serological parameters.

Inoculation through the natural, oronasal route invariably initiated an immediate infection as judged by the rapid onset of shedding of virus with the faeces. At the highest doses shedding started already at day 1 (strain UCD) and 2 (strain RM), at lower doses within three days after inoculation. Titres rose rapidly, peaking about two days later at $10^{6}-10^{8}$ genome equivalents $/ \mu \mathrm{L}$ irrespective of the dose and staying high thereafter for the next 2 to 3 weeks. Shedding continued during the subsequent two months at a gradually but slowly decreasing level except for the four animals inoculated with the lowest FECV RM doses, which all ceased shedding from about 6 weeks onwards. These results are in part consistent with a study by Pedersen et al. [24] in which experimentally infected cats were systematically monitored over longer (8-48 months) periods. Based on the shedding patterns of the 29 cats that had been inoculated orally with (an unknown dose of) FECV strain RM, the authors of this study distinguished three excretion types: persistent, intermittent and self-limiting. Though our monitoring period was too short to allow such classification, the shedding patterns we observed 
with this RM strain indicate that the inoculation dose can affect the type of excretion, lower doses giving rise to earlier clearance of the infection than higher doses. This is remarkable in view of the comparable excretion levels at the peak of shedding. For the UCD strain this distinction could not be made.

Within the range of inoculation doses that we used in our dose titration experiments, the threshold below which infection becomes ineffective was not reached. The observations in Figure 1 suggest that rather low doses are probably sufficient to establish FECV infection, consistent with the efficient spread of the virus in the field. For FECV UCD our lowest dose was $5 \times 10^{5}$ genome equivalents. The average amount of this virus shed during the first 45 days of the infection was around $5 \times 10^{5}$ genomes/ $\mu \mathrm{L}$. From this it is clear that only traces of the faeces from such infected cats will already suffice to initiate an infection in a new host.

All FECV UCD and FECV RM infected cats seroconverted starting approximately 10 days after inoculation. During the next weeks the serum IgG titres increased but they never reached high levels. These systemic antibodies, which were directed against all major viral structural proteins, were obviously unable to efficiently clear the local FECV infection as shedding of virus with the faeces continued in their presence. Our observations are consistent with the few reports regarding immune responses to experimental FECV infection, and in which low and often variable antibody titres were found in serum or plasma [21, 24, 26]. Little is known about mucosal immune responses to FECV infection in the gut. Though probably the most important for the control and clearance of the infection, local immunity is evidently inadequate. It is quite conceivable that this failure is due to interference of viral factors with the immune system.

FECV replicates in the gastrointestinal tract $[13,23]$. Using RT-PCR, viral RNA has however also been observed by us [12, 13, 28] and others $[7,17,18,21]$ in blood, some organs and haemolymphatic tissues of naturally infected cats; in experimentally infected animals viral RNA appeared hard to detect in PBMC (this study) or blood monocytes [21].
The significance of the apparent viraemia is still enigmatic. While cells of the monocyte lineage are the prime targets of FIPV, these cells are poorly susceptibility to FECV and support its replication and spread very inefficiently, at least in vitro [27, 29]. In one study using blood from 22 cats, the monocytes from three cats were not susceptible to FECV while the cells from the other animals could be infected but did not sustain the infection [5]. Studies using an RT-PCR targeting viral mRNA to detect FCoV replication suggest this situation to be the case as well in vivo [13, 28]; actually, viral mRNA or infected cells could not be observed in organs other than the intestinal tract. Apparently, FECV is picked up by mononuclear cells in the gut and carried to organs and tissues with the blood. Consistently, while studying haemolymphatic tissues, a major site for the accumulation of monocytes/macrophages, Kipar et al. found significantly higher levels of viral RNA in cats with FIP than in healthy FCoV positive cats [17]. Moreover, FCoV antigen was detectable by immunohistology in these tissues only in FIP cats $[17,18]$, confirming the low FECV replication activity in the mononuclear cells.

FECV is tropic for cells of the mature apical epithelium of the intestinal villi, targeting cells from the caudal part of the duodenum to the cecum during acute infection [23]. In chronically infected animals the lower part of the gastrointestinal tract was identified as a major site of viral replication, as indicated by RT-PCR detection of viral mRNA and by immunohistochemical detection of infected cells [13]. Consistent with these findings, during experimentally established persistent infection we only observed FECV in the large intestine, downstream of the appendix, i.e. in colon and rectum. During the submission process of this manuscript a publication by Kipar et al. [19] appeared in which the colon was also identified as the major site of FCoV persistence.

FECV are known as low- or non-virulent pathogens. Whether and to what extent virulence variation occurs is not really clear; no virulence variants have so far been described. Here we studied two independent FECV strains isolated from cats many years apart and maintained by cat-to-cat passage only. Interestingly, the two viruses behaved reproducibly different, 
the UCD strain being consistently more pathogenic than the RM strain, also when applied to older kittens (data not shown). In both infection experiments with FECV RM the cats grew normally, remained without fever, produced normal stools and did not show obvious signs of disease. In contrast, the FECV UCD infected cats had diminished appetite and exhibited weight loss early after inoculation. Two of the cats developed chronic or recurrent fever, as observed also with another FECV isolate [21]. The results indicate that variation in FECV pathogenicity does indeed occur. Still, these viruses seem to have evolved a rather harmonious relationship with their host, a peaceful coexistence that is threatened only by the ability of these viruses to suddenly turn into killers, FIPV. It remains enigmatic how, why and to what evolutionary advantage this mutational feature is apparently being conserved so well.

Acknowledgements. We are very grateful to Raoul de Groot for stimulating discussions and advise. We also want to acknowledge the assistance and animal care provided by the employees of the Central Animal Laboratory of the Utrecht University.

\section{REFERENCES}

[1] Addie D.D., Jarrett O., A study of naturally occurring feline coronavirus infections in kittens, Vet. Rec. (1992) 130:133-137.

[2] Addie D.D., Jarrett O., Use of a reverse-transcriptase polymerase chain reaction for monitoring the shedding of feline coronavirus by healthy cats, Vet. Rec. (2001) 148:649-653.

[3] Boom R., Sol C.J., Salimans M.M., Jansen C.L., Wertheim-van Dillen P.M., van der Noordaa J., Rapid and simple method for purification of nucleic acids, J. Clin. Microbiol. (1990) 28:495-503.

[4] Chang H.W., de Groot R.J., Egberink H.F., Rottier P.J., Feline infectious peritonitis: insights into feline coronavirus pathobiogenesis and epidemiology based on genetic analysis of the viral $3 \mathrm{c}$ gene, J. Gen. Virol. (2010) 91:415-420.

[5] Dewerchin H.L., Cornelissen E., Nauwynck H.J., Replication of feline coronaviruses in peripheral blood monocytes, Arch. Virol. (2005) 150:2483-2500.

[6] Foley J.E., Poland A., Carlson J., Pedersen N.C., Patterns of feline coronavirus infection and fecal shedding from cats in multiple-cat environments, J. Am. Vet. Med. Assoc. (1997) 210:1307-1312.

[7] Gunn-Moore D.A., Gruffydd-Jones T.J., Harbour D.A., Detection of feline coronaviruses by culture and reverse transcriptase-polymerase chain reaction of blood samples from healthy cats and cats with clinical feline infectious peritonitis, Vet. Microbiol. (1998) 62:193-205.

[8] Gunn-Moore D.A., Gunn-Moore F.J., GruffyddJones T.J., Harbour D.A., Detection of FCoV quasispecies using denaturing gradient gel electrophoresis, Vet. Microbiol. (1999) 69:127-130.

[9] Gut M., Leutenegger C.M., Huder J.B., Pedersen N.C., Lutz H., One-tube fluorogenic reverse transcription-polymerase chain reaction for the quantitation of feline coronaviruses, J. Virol. Methods (1999) 77:37-46.

[10] Haijema B.J., Volders H., Rottier P.J.M., Live, attenuated coronavirus vaccines through the directed deletion of group-specific genes provide protection against feline infectious peritonitis, J. Virol. (2004) 78:3863-3871.

[11] Haijema B.J., Rottier P.J., de Groot R.J., Feline coronaviruses: a tale of two-faced types, Caister Academic Press, Norfolk, UK, 2007, pp. 183-203.

[12] Herrewegh A.A., de Groot R.J., Cepica A., Egberink H.F., Horzinek M.C., Rottier P.J., Detection of feline coronavirus RNA in feces, tissues, and body fluids of naturally infected cats by reverse transcriptase PCR, J. Clin. Microbiol. (1995) 33:684-689.

[13] Herrewegh A.A., Mahler M., Hedrich H.J., Haagmans B.L., Egberink H.F., Horzinek M.C., et al., Persistence and evolution of feline coronavirus in a closed cat-breeding colony, Virology (1997) 234: 349-363.

[14] Hickman M.A., Morris J.G., Rogers Q.R., Pedersen N.C., Elimination of feline coronavirus infection from a large experimental specific pathogen-free cat breeding colony by serologic testing and isolation, Feline Pract. (1995) 23:96-102.

[15] Hohdatsu T., Okada S., Koyama H., Characterization of monoclonal antibodies against feline infectious peritonitis virus type II and antigenic relationship between feline, porcine, and canine coronaviruses, Arch. Virol. (1991) 117:85-95.

[16] Hohdatsu T., Okada S., Ishizuka Y., Yamada H., Koyama H., The prevalence of types I and II feline coronavirus infections in cats, J. Vet. Med. Sci. (1992) 54:557-562.

[17] Kipar A., Baptiste K., Barth A., Reinacher M., Natural FCoV infection: cats with FIP exhibit 
significantly higher viral loads than healthy infected cats, J. Feline Med. Surg. (2006) 8:69-72.

[18] Kipar A., Meli M.L., Failing K., Euler T., Gomes-Keller M.A., Schwartz D., et al., Natural feline coronavirus infection: Differences in cytokine patterns in association with the outcome of infection, Vet. Immunol. Immunopathol. (2006) 112:141-155.

[19] Kipar A., Meli M.L., Baptiste K.E., Bowker L.J., Lutz H., Sites of feline coronavirus persistence in healthy cats, J. Gen. Virol. (2010) 91:1698-1707.

[20] Lutz H., Lehmann R., Winkler G., Kottwitz B., Dittmer A., Wolfensberger C., Arnold P., Feline immunodeficiency virus in Switzerland: clinical aspects and epidemiology in comparison with feline leukemia virus and coronaviruses, Schweiz. Arch. Tierheilkd. (1990) 132:217-225 (in German).

[21] Meli M., Kipar A., Müller C., Jenal K., Gönczi E., Borel N., et al., High viral loads despite absence of clinical and pathological findings in cats experimentally infected with feline coronavirus (FCoV) type I and in naturally FCoV-infected cats, J. Feline Med. Surg. (2004) 6:69-81.

[22] Pedersen N.C., Boyle J.F., Floyd K., Infection studies in kittens, using feline infectious peritonitis virus propagated in cell culture, Am. J. Vet. Res. (1981) 42:363-367.

[23] Pedersen N.C., Boyle J.F., Floyd K., Fudge A., Barker J., An enteric coronavirus infection of cats and its relationship to feline infectious peritonitis, Am. J. Vet. Res. (1981) 42:368-377.
[24] Pedersen N.C., Allen C.E., Lyons L.A., Pathogenesis of feline enteric coronavirus infection, J. Feline Med. Surg. (2008) 10:529-541.

[25] Pedersen N.C., A review of feline infectious peritonitis virus infection: 1963-2008, J. Feline Med. Surg. (2009) 11:225-258.

[26] Poland A.M., Vennema H., Foley J.E., Pedersen N.C., Two related strains of feline infectious peritonitis virus isolated from immunocompromised cats infected with a feline enteric coronavirus, J. Clin. Microbiol. (1996) 34:3180-3184.

[27] Rottier P.J., Nakamura K., Schellen P., Volders H., Haijema B.J., Acquisition of macrophage tropism during the pathogenesis of feline infectious peritonitis is determined by mutations in the feline coronavirus spike protein, J. Virol. (2005) 79:14122-14130.

[28] Simons F.A., Vennema H., Rofina J.E., Pol J.M., Horzinek M.C., Rottier P.J., Egberink H.F., A mRNA PCR for the diagnosis of feline infectious peritonitis, J. Virol. Methods (2005) 124:111-116.

[29] Stoddart C.A., Scott F.W., Intrinsic resistance of feline peritoneal macrophages to coronavirus infection correlates with in vivo virulence, J. Virol. (1989) 63:436-440.

[30] Vennema H., Poland A., Foley J., Pedersen N.C., Feline infectious peritonitis viruses arise by mutation from endemic feline enteric coronaviruses, Virology (1998) 243:150-157 